\title{
Article \\ Evolutionary Game of Small and Medium-Sized Enterprises' Accounts-Receivable Pledge Financing in the Supply Chain
}

\author{
Haiju Hu *, Yakun Li (D, Mao Tian and Xinjiang Cai \\ School of Economics and Management, Yanshan University, Qinhuangdao 066000, China; \\ liyakun@stumail.ysu.edu.cn (Y.L.); tianmaoemail@163.com (M.T.); xinjiangcai@ysu.edu.cn (X.C.) \\ * Correspondence: huhaiju@ysu.edu.cn
}

Citation: Hu, H.; Li, Y.; Tian, M.; Cai, X. Evolutionary Game of Small and Medium-Sized Enterprises' Accounts-Receivable Pledge Financing in the Supply Chain. Systems 2022, 10, 21. https:// doi.org/10.3390/systems10010021

Academic Editor:

Evangelos Katsamakas

Received: 17 January 2022

Accepted: 15 February 2022

Published: 17 February 2022

Publisher's Note: MDPI stays neutral with regard to jurisdictional claims in published maps and institutional affiliations.

Copyright: () 2022 by the authors. Licensee MDPI, Basel, Switzerland. This article is an open access article distributed under the terms and conditions of the Creative Commons Attribution (CC BY) license (https:/ / creativecommons.org/licenses/by/ $4.0 /)$.

\begin{abstract}
Due to limited guarantees, it is difficult for small and medium-sized enterprises (SMEs) to obtain loans from banks. Supply chain accounts-receivable pledge financing (SCARPF) can help in overcoming those financing difficulties. This study developed an evolutionary game model of banks, core enterprises and SMEs in SCARPF, analyzed the evolution path and evolution rules of the model, and performed a numerical simulation. The results indicated that the result of the evolutionary game depends on the initial values of the variables. When certain conditions are met, the system will evolve to (lending, keep the contract). The higher the return rate during either normal production of SMEs, the loan interest rate or supply chain punishment, the more likely it is that banks will lend money and SMEs will keep the contract. However, the bank will only be likely to lend money, enabling SMEs to keep the contract, when the probability of core enterprises and SMEs engaging in joint loan fraud-or the proportion of the benefits that SMEs share when engaging in joint loan fraud-is reduced. The results of this study provide insights for banks, core enterprises, and SMEs in supply chain financing decisions, which is conducive to solving the financing difficulties of SMEs.
\end{abstract}

Keywords: supply chain accounts-receivable pledge financing; small and medium-sized enterprises; supply chain financing; evolutionary game

\section{Introduction}

With the impact of the Coronavirus pandemic in 2019 (COVID-19), small and mediumsized enterprises (SMEs) are facing serious problems such as tight cash flow, slow progress in resuming production and work, and a sharp decline in foreign trade orders. Therefore, they are in urgent need of financing assistance. However, it is difficult for SMEs to obtain loans from banks due to their own development restrictions [1-3]. According to China's small, medium and micro enterprises' Financial Services Development Report, the difficult and expensive financing situation faced by SMEs, lacking mortgages and guarantees in bank financing, can hardly be improved in a short period of time [4]. Barkley et al. [5] conducted a credit survey on 3459 SMEs in the United States and found that $47 \%$ of SMEs need to apply for financial assistance. There is a similar case in developing countries, where financing difficulties are also a common problem for many SMEs [6,7]. About half of the SMEs in developing countries have applied for financial assistance [8]. However, only 4.7\% of working capital loans and $23.3 \%$ of bank loans in China are issued to SMEs [9].

To solve the financing problem of SMEs, supply chain financing has been extensively studied [10]. Among supply chain financing models, the supply chain accounts-receivable pledge financing (SCARPF) model is the most widely used model [11]. SCARPF is a financing method in which borrowers transfer accounts receivable to banks and other institutions to obtain bank loans. It is conducive to the settlement of corporate triangle debts and the alleviation corporate financing difficulties. In SCARPF, it is urgent to study how to make strategic choices for SMEs to obtain more financing opportunities, and how to make strategic choices for participants to obtain more profits. Therefore, this paper 
uses the evolutionary game theory to analyze the participants' selection of strategies in SCARPF. Conditions under which the bank will lend money, wherein the SME and the core enterprise will keep the contract, are obtained. Through this paper, we strive to provide suggestions for SMEs to obtain more financing resources, and also provide guidance for other participants in the supply chain.

The remainder of this paper is organized as follows: Section 2 discusses related literature, Section 3 builds and analyzes the evolutionary game model, Section 4 provides a numerical simulation, Section 5 presents the research results, and conclusions are given in Section 6.

\section{Literature Review}

Supply chain financing is a financial management method that allows funds in the supply chain to flow, thus improving the value of the entire supply chain [12]. Jing and Seidmann [13] view supply chain financing as a process of optimizing supply chain management around core enterprises. Caniato et al. [14] believe that supply chain financing can solve the problems of the corporate credit crunch and increase financing costs. Based on the above research, supply chain financing is a financing activity aimed at solving the financing difficulties of the upstream and downstream companies in the supply chain, and increasing the value of supply chain members. Supply chain financing can effectively reduce information asymmetry between borrowers and lenders, and improve the efficiency of SMEs' financing in the supply chain [12,15]. However, SCARPF, as the most widely used supply chain financing model, has not received enough attention. Therefore, this paper focuses on SCARPF, which will help to enrich the research on supply chain financing.

Game theory is often used by researchers to build and solve models in the supply chain management area. In the field of supply chain financing, game theory is also widely used [16-18]. Yan et al. [19] established a two-stage Stackelberg game model consisting of the retailer, the manufacturer and the bank, and analyzed the interdependence between the business decisions and financial decisions of the retailer. Zhao and Duan [20] used game models to study the coordination mechanism of supply chain financing, and analyzed the decision-making problems of suppliers, retailers and banks. Gao et al. [21] used the Stackelberg game to analyze the optimal decision of each participant based on the P2P supply chain financing platform, under the condition of uncertain demand. Bank financing and trade credit financing in the supply chain are compared [22,23]. Yang et al. [24] studied the decision of whether a manufacturer with limited funds, as a new entrant in the supply chain, should choose retailer financing or bank financing. Luo et al. [25] studied whether retailers with limited funds should carry out manufacturer financing or bank financing and obtained the corresponding conditions. An et al. [26] studied green credit financing in the supply chain and found that the manufacturer maximizes profits through green credit financing from the bank. The government can set different carbon emission caps to achieve a win-win situation for social welfare and manufacturer profits. Existing research mainly studies optimal decision making under supplier financing, retailer financing and bank financing from a completely rational perspective of supply chain members [27,28].

The above research is based on the complete rationality of supply chain members, but the supply chain members in reality are bounded rational. Therefore, it is necessary to study the strategic choices of the supply chain members from the perspective of bounded rationality. The evolutionary game theory assumes that the players in the game are bounded rational. It is believed that the players cannot respond quickly and optimally to changes in information, and the behavior of the players is a process of dynamic adjustment [29]. Few works of literature use evolutionary game methods to study finance in the supply chain $[30,31]$, and studies of SCARPF have not been found.

The literature most relevant to our paper is summarized in Table 1 . In contrast to the literature that studies capital-constrained manufacturers or retailers, this paper conducts supply chain finance analysis directly from the perspective of SMEs. This paper uses the evolutionary game method to study the strategic choices of SCARPF participants, 
which can obtain more realistic decision-making results. The innovation of this paper is to construct a tripartite evolutionary game model of the bank, the core enterprise and the SME, and consider joint loan fraud between the core enterprise and the SME. The stability of the system is analyzed, providing meaningful insights for the dynamic strategic evolution process of supply chain members.

Table 1. Comparison of the related literature.

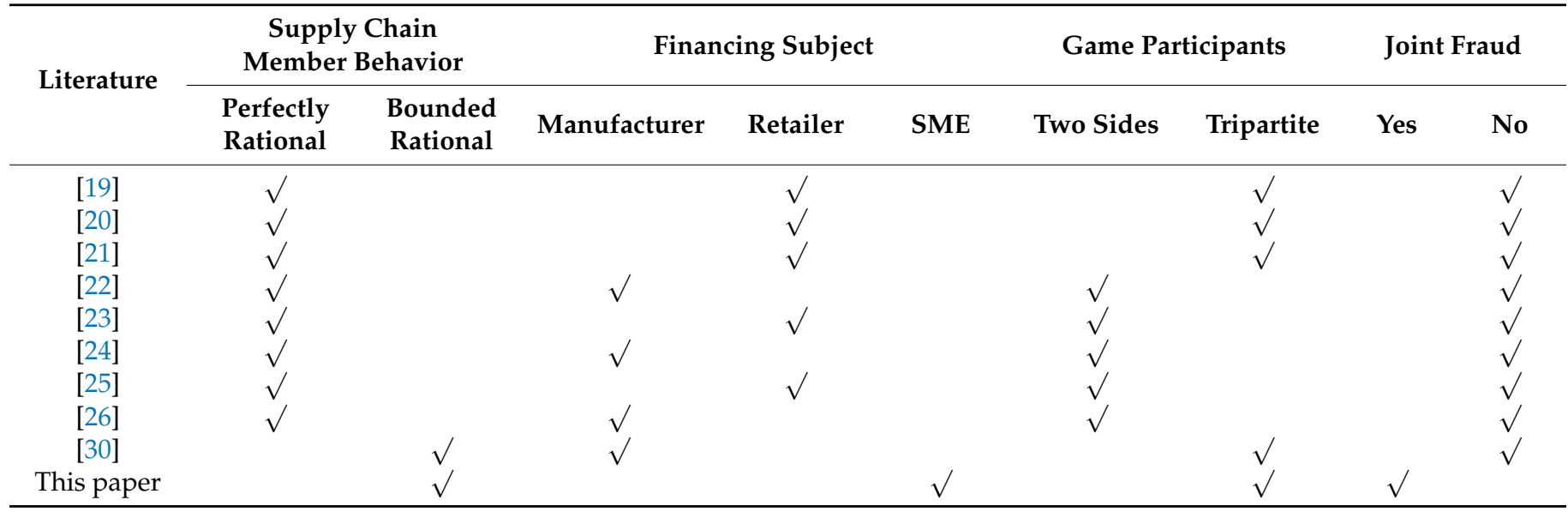

\section{Evolutionary Game Analysis of SCARPF}

\subsection{Business Process of SCARPF}

This study focused on the supply chain in which SMEs provide parts for core enterprises. Figure 1 shows the business process for the SME to carry out SCARPF. The specific process is as follows:

1. The SME trades with the core enterprise to generate accounts receivable;

2. The SME in the upstream of the supply chain submits an application for SCARPF to the bank;

3. After receiving the SME financing application, the bank confirms the creditor's rights to these accounts receivable to the downstream core enterprise;

4. After the creditor's rights to the core enterprise's bill are confirmed, the bank and the SME will sign an agreement on financing matters to lend to SMEs. At the same time, the SME establishes a collection account in the bank and informs the core enterprise;

5. The core enterprise will transfer the accounts receivable to the collection account by the due date of the agreed financing period;

6. The bank will liquidate the financing and transfer the remaining funds to the SME after deducting the income.

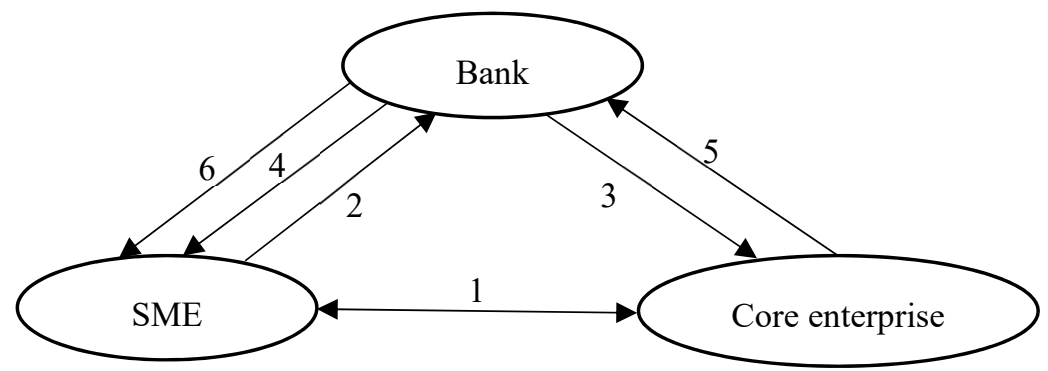

Figure 1. SCARPF business flow. 


\subsection{The Strategic Space of Supply Chain Members}

In the process of supply chain financing, neither banks nor SMEs are entirely rational. That is, neither agent can reach the Nash equilibrium through a single game. Therefore, this section attempts to analyze the equilibrium state of the game model from the perspective of an evolutionary game, which aims to present a theoretical basis for banks and SMEs to jointly form a good financing relationship.

In the evolutionary game of SCARPF, the strategic space of the bank is (lending, no lending). "Lending" refers to the bank making lending decisions after receiving financing applications from the SME. "No lending" means that the bank makes a decision not to lend after receiving the financing application from the SME. The strategic space for the SME is (keep the contract, break the contract). "Break the contract" means that the SME refuses to repay the principal and interest of the bank when the core enterprise transfers account receivable to the collection account. "Keep the contract" means that when the core enterprise transfers the account receivable into the collection account, the SME agrees with the bank to deduct the principal and interest, in order to make liquidation treatment. Due to the fact that in reality, it is impossible for the core enterprise to default on the premise that the creditor's rights have been confirmed, the core enterprise is more concerned about joint loan fraud with the SME. The strategic space of the core enterprise is (joint loan fraud, no joint loan fraud). "No joint loan fraud" means that the core enterprise transfers the accounts receivable to the collection account after the agreed financing period is reached.

\subsection{Model Specification}

In the early days of SCARPF, it was difficult for participants to pursue a balanced development of their own interests. Therefore, it was necessary to make decisions according to their own needs during the difficult trial and error process, allowing participants to explore each other during the dynamic game process and optimize their choices. To develop an effective evolutionary game, the following assumptions are made:

(1) The total number of accounts receivable of the SME is $A$. The rate of return for normal production of the SME is $r_{1}$. The rate of return for normal production of the core enterprise is $r_{2}$.

(2) The bank's pledge rate for accounts receivable is $\lambda$. The interest rate is $r_{0}$. The financing period is 1 year. The supervision cost of a single SCARPF is $C\left(C<\lambda A r_{0}\right)$. The probability that the bank chooses the lending strategy is $x(0 \leq x \leq 1)$, then the probability that the bank chooses the non-lending strategy is $1-x$.

(3) The unilateral breach of the contract by the SME has caused losses in the creditworthiness of the core enterprise. The core enterprise will punish the SME, that is, punishment from the supply chain, such as reducing cooperation opportunities or terminating cooperation, which is recorded as $F$. Due to the unilateral default of the SME, based on the confirmation of the creditor's rights of the core enterprise bill, the core enterprise must pay $M\left(0<M<\lambda A\left(1+r_{0}\right)\right)$ to the bank according to the agreement. The probability that the SME breaks the contract is $y(0 \leq y \leq 1)$, and the probability that the SME keeps the contract is $1-y$.

(4) The probability of core enterprise and SME joint loan fraud is $\alpha(0 \leq \alpha \leq 1)$. The benefits of core enterprise and SME joint loan fraud will be distributed between the SME and the core enterprise. The proportion of the benefits received by the SME is $\beta(0<\beta<1)$. The proportion of benefits received by the core enterprise is $1-\beta$.

(5) The SME can obtain financing to produce, and due to the important position of the core enterprise in the business of the SME, the SME will give priority to meeting the procurement needs of the core enterprise. At the same time, the SME will supply the core enterprise in a fixed cycle and fixed batch. SCARPF is based on the confirmation of the creditor's rights relationship of the core enterprise, so when the SME can obtain financing, it will meet the core enterprise's procurement needs. However, when the SME unilaterally breaks the contract, it will not supply the core enterprise. 
When the SME chooses the strategy to keep the contract, the fraud of the joint loan becomes meaningless. Therefore, considering joint loan fraud should be based on the premise that the SME will default. Therefore, feasible strategy combinations are: the bank, the SME (lending, keep the contract); the bank, the SME (no lending, keep the contract); the bank, the core enterprise, the SME (lending, no joint loan fraud, break the contract); the bank, the core enterprise, the SME (no lending, no joint loan fraud, break the contract); the bank, the core enterprise, the SME (lending, joint loan fraud, break the contract); the bank, the core enterprise, the SME (no lending, joint loan fraud, break the contract).

Based on the above assumptions, the incomes of each participant under different strategy combinations are obtained:

(1) When the bank decides to lend to the SME, the SME can also keep the contract when the core enterprise transfers the accounts receivable to the collection account. That is, the strategic combination of the bank and the SME is (lending, keep the contract). At this time, the three-party income expressions of the bank, the core enterprise and the SME are $\lambda A r_{0}-C, A r_{2}, \lambda A\left(r_{1}-r_{0}\right)$, respectively.

(2) When the bank decides not to lend to the SME, due to the constraints of procurement contracts between the SME and the core enterprise, and considering the impact of the core enterprise on the business of the SME, the SME will still give priority to meeting the procurement needs of the core enterprise. The strategic combination of the bank and the SME is (no lending, keep the contract). At this time, the three-party income expressions of the bank, the core enterprise and the SME are $0, A r_{2}, 0$, respectively.

(3) When the bank decides to lend to the SME and there is no joint loan fraud between the core enterprise and the SME, the SME unilaterally breaks the contract. In this case, the strategic combination of the bank, the core enterprise, and the SME is (lending, no joint loan fraud, break the contract). At this time, the three-party income expressions of the bank, the core enterprise and the SME are $-\lambda A\left(1+r_{0}\right)-C+M$, $-A r_{2}-M, \lambda A\left(1+r_{0}\right)-A-F$, respectively.

(4) When the bank decides not to lend to the SME, the SME unilaterally breaks the contract. That is, the strategic combination of the bank, the core enterprise, and the SME is (no lending, no joint loan fraud, break the contract). At this time, the threeparty income expressions of the bank, the core enterprise and the SME are $0,-A r_{2}$, $-A-F$, respectively.

(5) When the bank decides to lend to the SME, and there is joint loan fraud between the core enterprise and the SME, the strategic combination of the bank, the core enterprise, and the SME is (lending, joint loan fraud, break the contract). At this time, the three-party income expressions of the bank, the core enterprise and the SME are $-\lambda A\left(1+r_{0}\right)-C, \lambda A\left(1+r_{0}\right)(1-\beta), \lambda A\left(1+r_{0}\right) \beta$, respectively.

(6) When the bank decides not to lend to the SME and there is no joint loan fraud between the core enterprise and the SME, the strategic combination of the bank, the core enterprise, and the SME is (no lending, joint loan fraud, break the contract). At this time, the three-party income expressions of the bank, the core enterprise and the SME are $0,0,0$, respectively.

According to the above combination of strategies, the income of the bank, the core enterprise and the SME can be summarized in Table 2. 
Table 2. The payoff matrix of the evolutionary game.

\begin{tabular}{cccc}
\hline \multirow{2}{*}{$\begin{array}{c}\text { SME Core } \\
\text { Enterprise Bank }\end{array}$} & \multicolumn{2}{c}{ Break the Contract $(\mathbf{y})$} & $\begin{array}{c}\text { Keep the Contract } \\
\mathbf{( 1 - y )}\end{array}$ \\
\cline { 2 - 4 } & Joint Loan Fraud $(\boldsymbol{\alpha})$ & $\begin{array}{c}\text { No Joint Loan Fraud } \\
\mathbf{( 1 - \alpha )}\end{array}$ & $\begin{array}{c}\lambda A r_{0}-C \\
\text { Lending }(x)\end{array}$ \\
& $\lambda A\left(1+r_{0}\right)(1-\beta)$ & $-\lambda A\left(1+r_{0}\right)-C+M$ & $A r_{2}$ \\
& $\lambda A\left(1+r_{0}\right) \beta$ & $\lambda A\left(1+r_{0}\right)-A-F$ & $\lambda A\left(r_{1}-r_{0}\right)$ \\
\hline \multirow{2}{*}{ No lending $(1-x)$} & 0 & 0 & 0 \\
& 0 & $-A r_{2}$ & $A r_{2}$ \\
\hline
\end{tabular}

\subsection{Stability and Evolution Path Analysis}

Suppose that the expected return under the bank's lending strategy is $u_{11}$; the expected return under the bank's no lending strategy is $u_{12}$; the total expected return is $\overline{u_{1}}$; and the bank's replication dynamic equation is $F_{x}$. From Table 2, we can obtain the income of the bank that chooses to lend or not lend, then:

$$
\begin{gathered}
u_{11}=y\left(\alpha\left[-\lambda A\left(1+r_{0}\right)-C\right]+(1-\alpha)\left[-\lambda A\left(1+r_{0}\right)-C+M\right]\right)+(1-y)\left(\lambda A r_{0}-C\right) \\
u_{12}=0
\end{gathered}
$$

Therefore, we can obtain:

$$
\overline{u_{1}}=x u_{11}+(1-x) u_{12}=x\left(\left(\lambda A r_{0}-C\right)-y\left[\lambda A\left(1+2 r_{0}\right)-(1-\alpha) M\right]\right)
$$

The bank's replication dynamic equation is:

$$
F_{x}=\frac{d x}{d t}=x\left(u_{11}-\overline{u_{1}}\right)=x(1-x)\left(\left(\lambda A r_{0}-C\right)-y\left[\lambda A\left(1+2 r_{0}\right)-(1-\alpha) M\right]\right)
$$

Suppose that the expected return of the SME strategy to break the contract is $u_{21}$; the expected return of the SME strategy to keep the contract is $u_{22}$; the total expected return is $\overline{u_{2}}$; and the SME's replication dynamic equation is $F_{y}$. From Table 2, we can obtain the income of the SME choosing to break the contract or keep the contract. Similarly, the replication dynamic equation of the SME can be obtained as:

$$
F_{y}=\frac{d y}{d t}=y(1-y)\left(-(1-\alpha)(A+F)+x \lambda A\left[(\alpha \beta-\alpha+1)-r_{0}(\alpha \beta-\alpha+2)-r_{1}\right]\right)
$$

The evolutionary game reaches the equilibrium state when both Equations (4) and (5) reach zero. Make $F_{x}=0$ and $F_{y}=0$. Therefore, there are five equilibrium points for the game: $E_{1}(0,0), E_{2}(0,1), E_{3}(1,0), E_{4}(1,1)$, and $E_{5}\left(x^{*}, y^{*}\right)$. When $(1-\alpha) M-$ $\lambda A\left(1+r_{0}\right)-C<0$ and $\lambda A\left[(\alpha \beta-\alpha+1)+r_{0}(\alpha \beta-\alpha+2)-r_{1}\right]-(1-\alpha)(A+F)>0$, $E_{5}\left(x^{*}, y^{*}\right)$ is an equilibrium point.

$$
x^{*}=\frac{(1-\alpha)(A+F)}{\lambda A\left[(\alpha \beta-\alpha+1)-r_{0}(\alpha \beta-\alpha+2)-r_{1}\right]}, y^{*}=\frac{\lambda A r_{0}-C}{\lambda A\left(1+2 r_{0}\right)-(1-\alpha) M} \text { in the above equation. }
$$

The equilibrium point $E_{3}(1,0)$ is the expected result of banks and SMEs. That is, the bank will lend to the SME and the SME will keep the contract. Supply chain members can gain more profits through SCARPF.

The stability analysis of the above five equilibrium points can be judged by the determinant and trace of the Jacobian matrix of the system [32]. By conducting partial derivatives of $x$ and $y$ in $F_{x}$ and $F_{y}$, we obtain the Jacobian matrix. Remember the Jacobian matrix symbol as $J$ :

$$
J=\left(\begin{array}{ll}
\frac{\partial F_{x}}{\partial x} & \frac{\partial F_{x}}{\partial y} \\
\frac{\partial F_{y}}{\partial x} & \frac{\partial F_{y}}{\partial y}
\end{array}\right)
$$


In the matrix above:

$$
\begin{gathered}
\frac{\partial F_{x}}{\partial x}=(1-2 x)\left(\left(\lambda A r_{0}-C\right)-y\left[\lambda A\left(1+2 r_{0}\right)-(1-\alpha) M\right]\right) \\
\frac{\partial F_{x}}{\partial y}=x(x-1)\left(\lambda A\left(2 r_{0}+1\right)-(1-\alpha) M\right) \\
\frac{\partial F_{y}}{\partial x}=y(1-y) \lambda A\left((\alpha \beta-\alpha+1)+(\alpha \beta-\alpha+2) r_{0}-r_{1}\right) \\
\frac{\partial F_{y}}{\partial y}=(1-2 y)\left((\alpha-1)(A+F)+x \lambda A\left[\left(1-r_{0}\right)(\alpha \beta-\alpha+1)-r_{0}-r_{1}\right]\right)
\end{gathered}
$$

For a discrete system, only when the determinant $($ det. $J>0)$ and trace $($ tr. $J<0)$ of the Jacobian matrix are satisfied at the same time is the equilibrium point an evolutionary stable strategy (ESS). By substituting the above five equilibrium points into the Jacobian

\begin{tabular}{|c|c|c|c|c|c|}
\hline & Condition & Equilibrium Point & det.J & $t r . J$ & Conclusion \\
\hline Case 1 & $\begin{array}{c}(1-\alpha) M-\lambda A\left(1+r_{0}\right)-C<0 \\
\lambda A\left[(\alpha \beta-\alpha+1)+r_{0}(\alpha \beta-\alpha+2)-r_{1}\right]- \\
(1-\alpha)(A+F)>0 .\end{array}$ & $\begin{array}{l}E_{1} \\
E_{2} \\
E_{3} \\
E_{4} \\
E_{5}\end{array}$ & $\begin{array}{l}- \\
- \\
- \\
- \\
+\end{array}$ & $\begin{array}{l}\text { uncertain } \\
\text { uncertain } \\
\text { uncertain } \\
\text { uncertain } \\
0\end{array}$ & $\begin{array}{l}\text { Saddle point } \\
\text { Saddle point } \\
\text { Saddle point } \\
\text { Saddle point } \\
\text { Central point }\end{array}$ \\
\hline Case 2 & $\begin{array}{c}(1-\alpha) M-\lambda A\left(1+r_{0}\right)-C<0 \\
\lambda A\left[(\alpha \beta-\alpha+1)+r_{0}(\alpha \beta-\alpha+2)-r_{1}\right]- \\
(1-\alpha)(A+F)<0 .\end{array}$ & $\begin{array}{l}E_{1} \\
E_{2} \\
E_{3} \\
E_{4} \\
E_{5}\end{array}$ & $\begin{array}{l}- \\
- \\
+ \\
+ \\
\text { / }\end{array}$ & $\begin{array}{c}\text { uncertain } \\
\text { uncertain } \\
- \\
+ \\
/\end{array}$ & $\begin{array}{c}\text { Saddle point } \\
\text { Saddle point } \\
\text { ESS } \\
\text { Unstable } \\
/\end{array}$ \\
\hline
\end{tabular}
matrix, finding the determinant and trace of each matrix, and judging the positive and negative of the determinant and trace of each matrix, we obtain Table 3.

Table 3. Stability judgment table for each equilibrium point.

The evolution phase diagrams for Case 1 and Case 2 are shown in Figures 2 and 3.

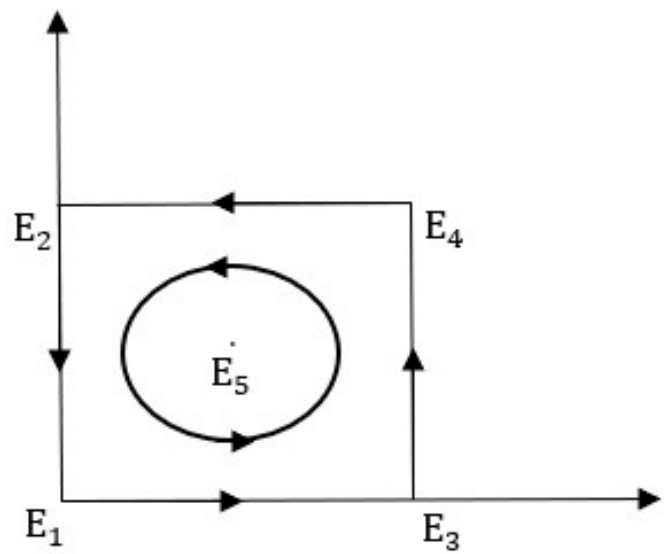

Figure 2. The evolution phase diagram for Case 1. 


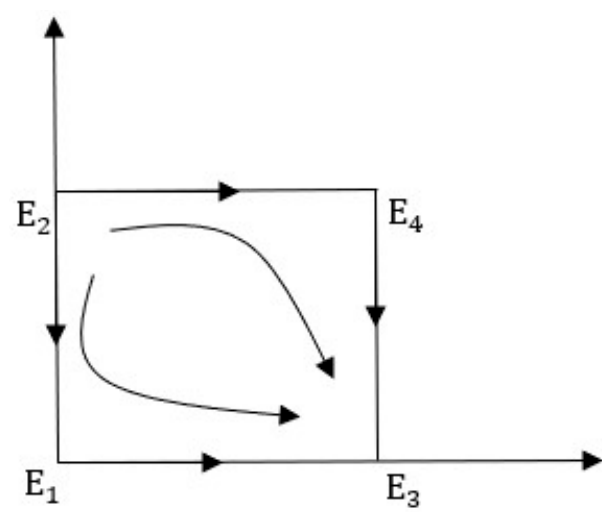

Figure 3. The evolution phase diagram for Case 2.

From the phase diagrams of Case 1 and Case 2, it can be clearly seen that there is no stable equilibrium solution in Case 1. That is, no matter where the initial state is in the region, the system will not have an evolutionary stable point, and there is no stable equilibrium solution for the bank and the SME. $E_{3}$ in Case 2 is an evolutionary stable equilibrium. That is, when $(1-\alpha) M-\lambda A\left(1+r_{0}\right)-C<0$ and $\lambda A\left[(\alpha \beta-\alpha+1)+r_{0}(\alpha \beta-\alpha+2)-r_{1}\right]-$ $(1-\alpha)(A+F)<0$ are satisfied, the system will evolve towards $E_{3}$. The bank will lend to the SME, and the SME will keep the contract.

\section{Numerical Simulation}

The case of the account receivable of a technology company in Shenzhen, China, was used for numerical simulation.

Take $A=$ CNY 38.1 million, and the supervision cost of single SCARPF of the bank is fixed at $C=$ CNY 0.01 million. In the SCARPF model, the bank's pledge rate $\lambda=0.7$, the interest rate $r_{0}=4.78 \%$, and the return rate of the SME during a normal production period $r_{1}=10 \%$. Based on the confirmation of the creditor's rights on the core enterprise bill, the core enterprise must pay the bank an amount of $M=C N Y 1.3$ million when the SME unilaterally defaults on the contract. When joint loan fraud occurs, the profit proportion of the SME is $\beta=0.5$. The probability that the core enterprise and the SME are involved in joint loan fraud is $\alpha=0.4$, and the supply chain penalty for a contract breach by the SME is $F=20$ million yuan. Assume that the initial values of the bank lending and the initial value of the SME breaking the contract are $x=0.5$ and $y=0.5$, respectively.

From the above values, the system evolution path diagram can be obtained as shown in Figure 4.

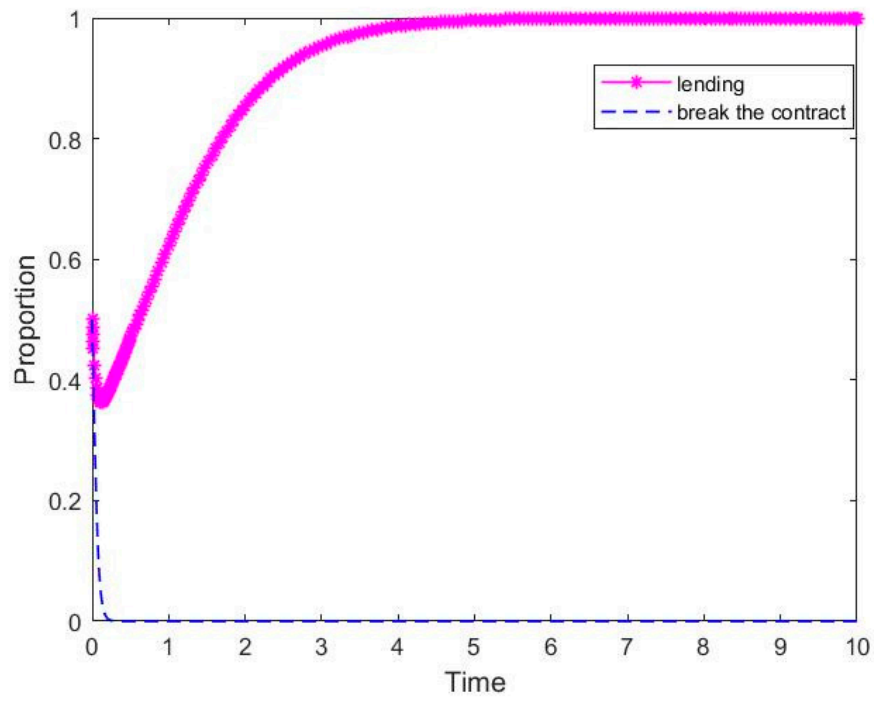

Figure 4. System evolution path diagram. 
It can be seen from Figure 4 that the game evolves towards $x=1$ and $y=0$, and the system has an ESS. This situation satisfies Case 2.

To explore the effect of joint loan fraud on the outcome of the evolutionary game, we set $\alpha=0$ and $\alpha=1$. Figures 5 and 6 can be obtained.

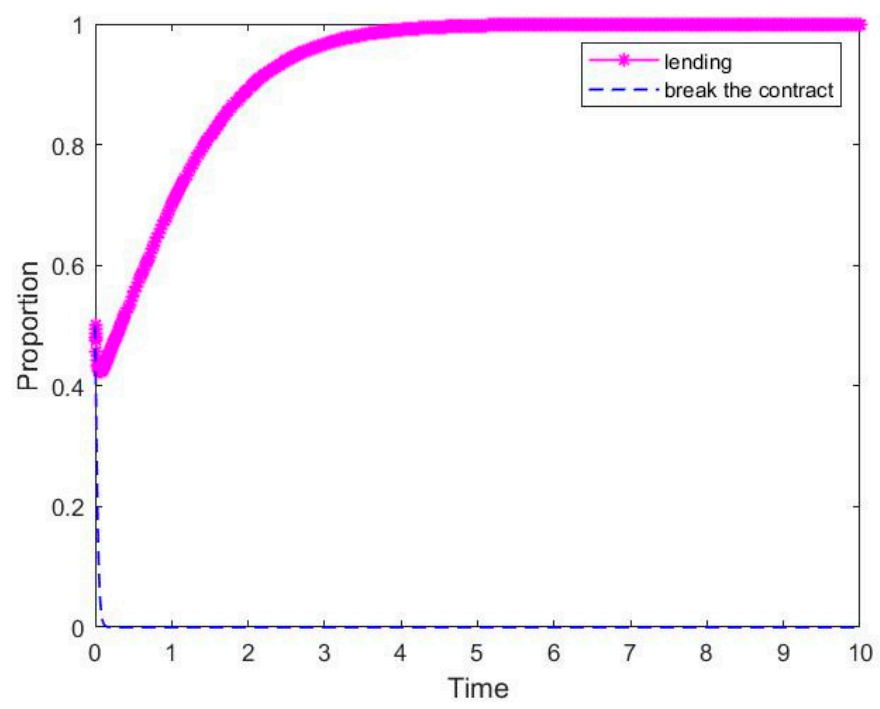

Figure 5. System evolution path diagram $(\alpha=0)$.

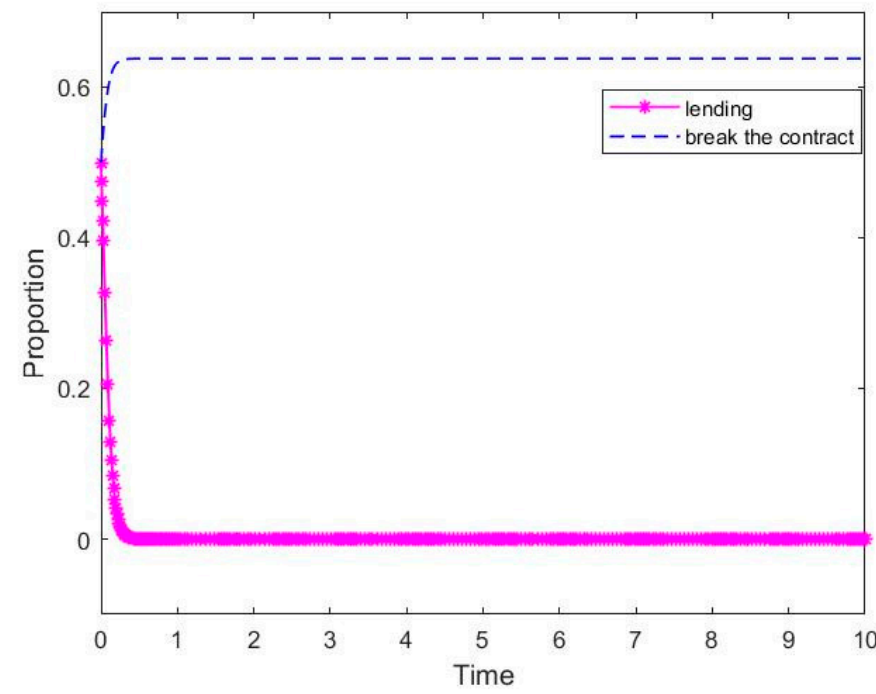

Figure 6. System evolution path diagram $(\alpha=1)$.

It can be seen from Figures 5 and 6 that the game evolves towards $x=1$ and $y=0$ when $\alpha=0$, and the game evolves towards $x=0$ and $y=0.65$ when $\alpha=1$. The situation when $\alpha=0$ satisfies Case 2, and the situation when $\alpha=1$ satisfies Case 1. Comparing Figures $4-6$, we can find that the smaller $\alpha$ is, the better the system will evolve towards (lending, keep the contract).

To explore the effect of the supply chain's penalty on the outcome of the evolutionary game, we set $F=0$ and $F=26.67$. Figures 7 and 8 can be obtained. 


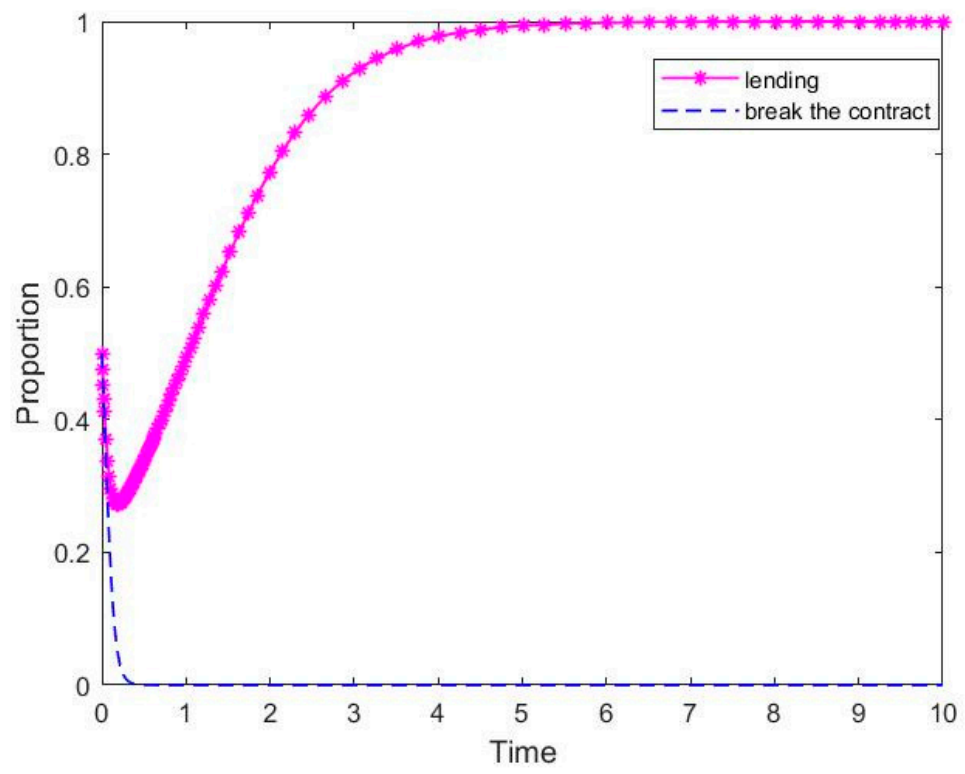

Figure 7. System evolution path diagram $(F=0)$.

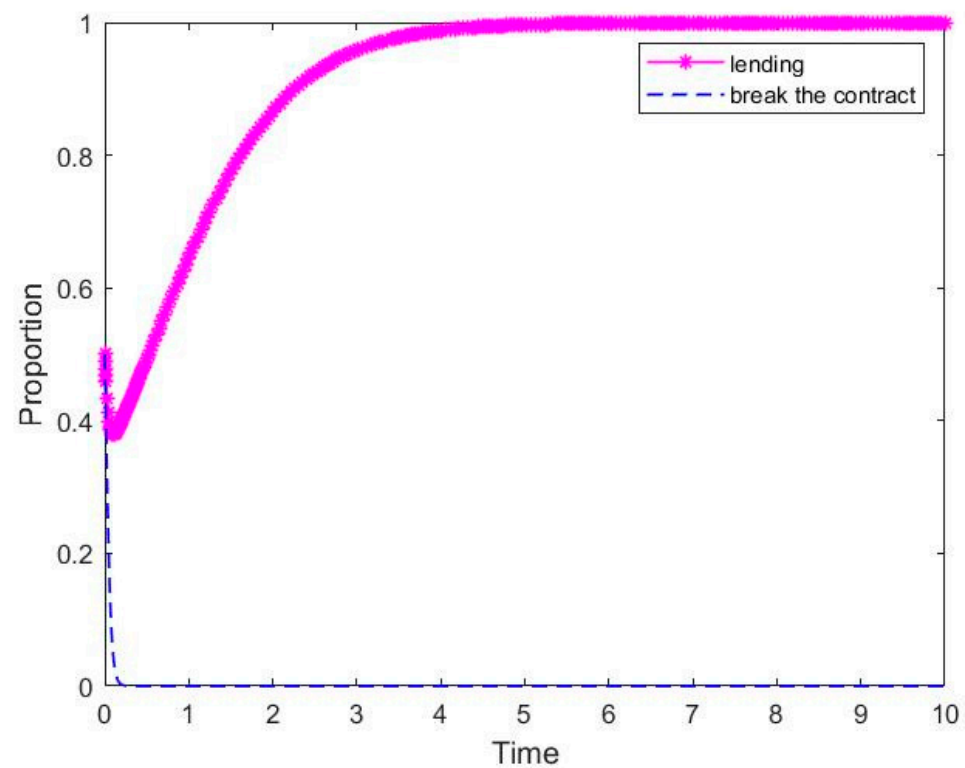

Figure 8. System evolution path diagram $(F=26.67)$.

It can be seen from Figures 7 and 8 that the game evolves towards $x=1$ and $y=0$. This situation satisfies Case 2. Comparing Figures 4, 7 and 8, we can find that the larger $F$ is, the better the system will evolve towards (lending, keep the contract).

To explore the effect of the proportion of the benefits on the outcome of the evolutionary game, we set $\beta=0$ and $\beta=1$. Figures 9 and 10 can be obtained. 


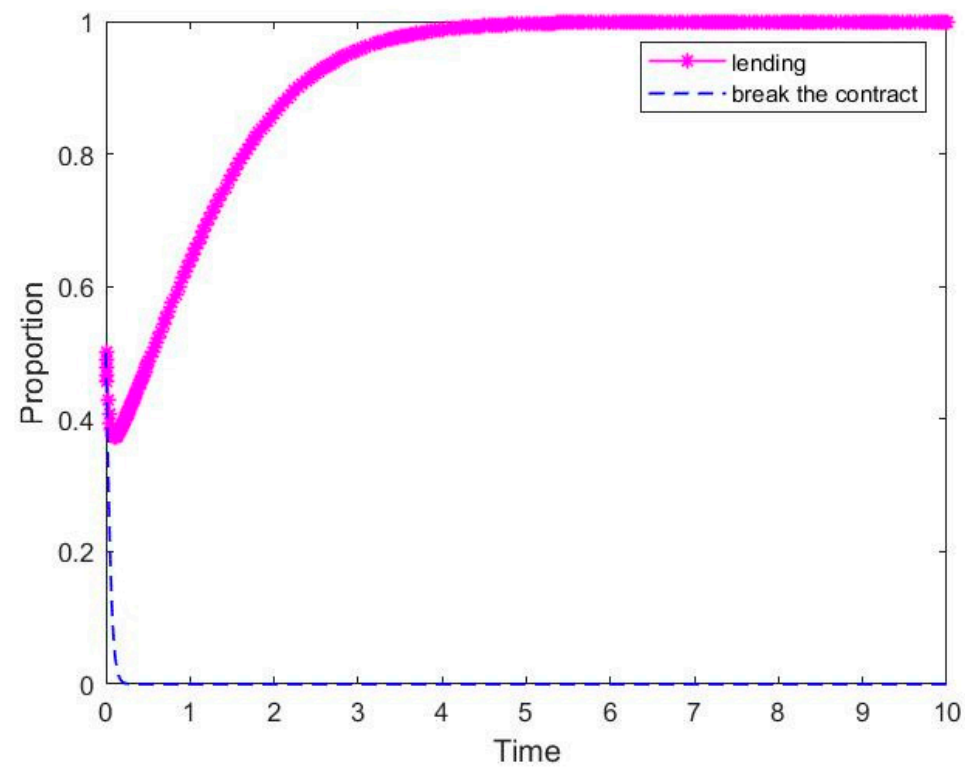

Figure 9. System evolution path diagram $(\beta=0)$.

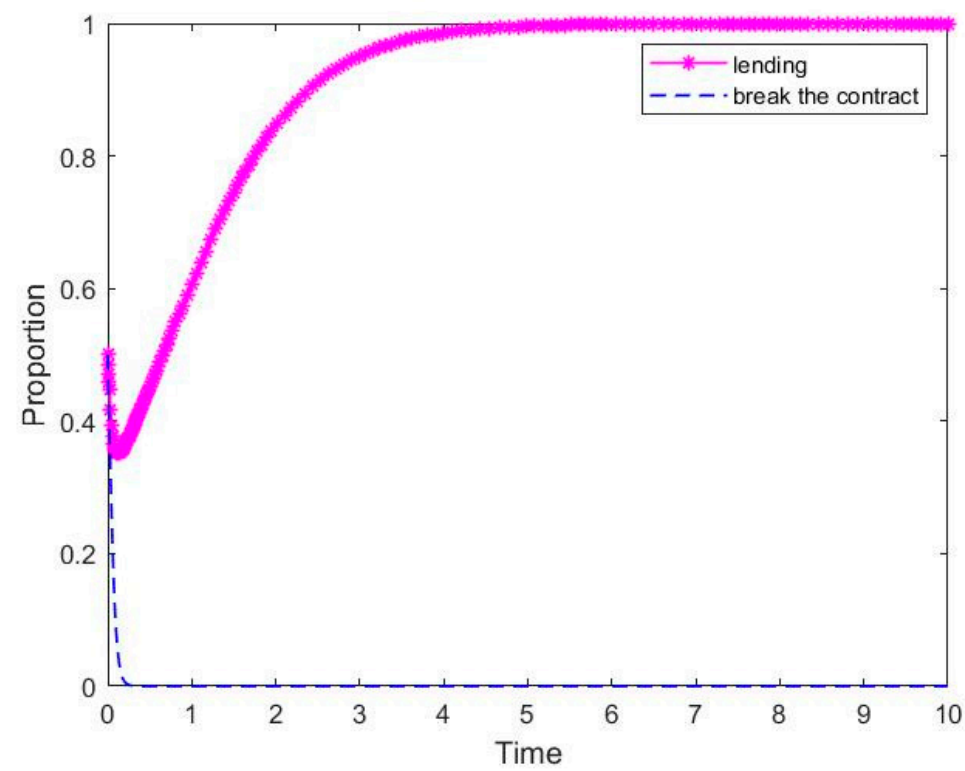

Figure 10. System evolution path diagram $(\beta=1)$.

It can be seen from Figures 9 and 10 that the game evolves towards $x=1$ and $y=0$. This situation satisfies Case 2. Comparing Figures 4, 9 and 10, we can find that the smaller $\beta$ is, the better the system will evolve towards (lending, keep the contract).

To explore the effect of the interest rate on the outcome of the evolutionary game, we set $r_{0}=1 \%$ and $r_{0}=10 \%$. Figures 11 and 12 can be obtained. 


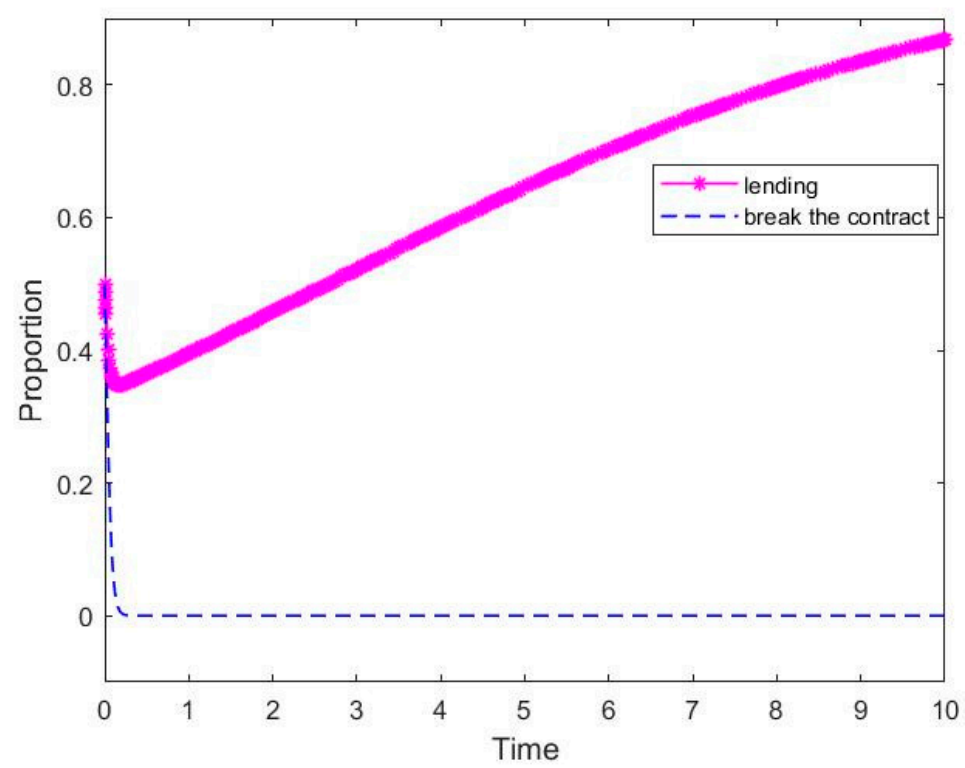

Figure 11. System evolution path diagram $\left(r_{0}=1 \%\right)$.

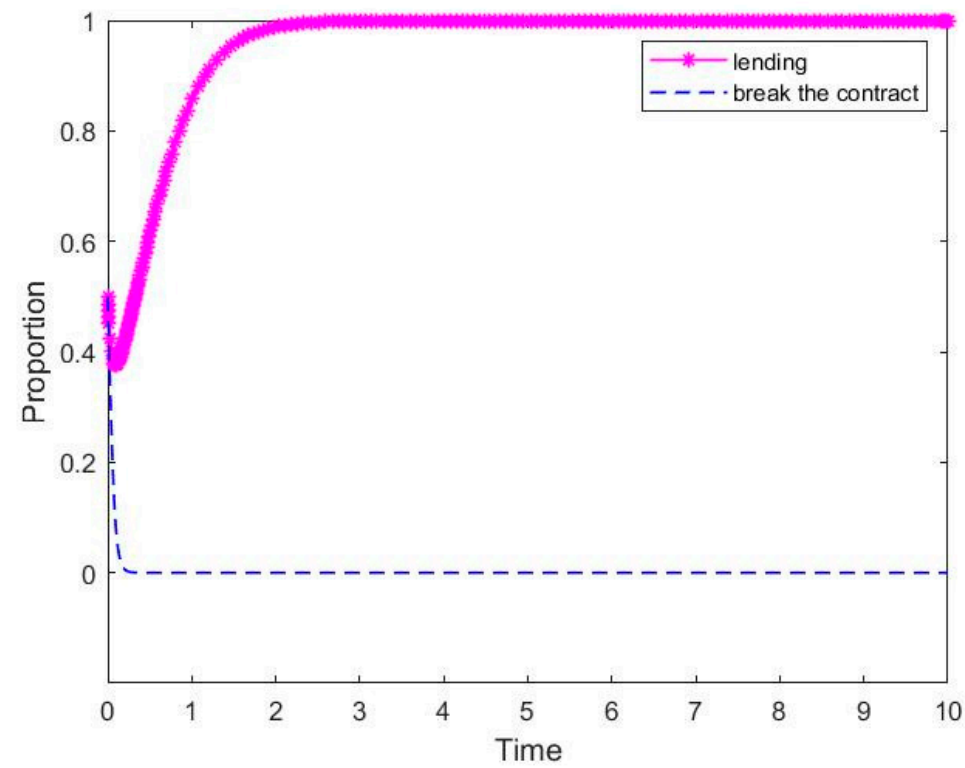

Figure 12. System evolution path diagram $\left(r_{0}=10 \%\right)$.

It can be seen from Figures 11 and 12 that the game evolves towards $x=1$ and $y=0$. This situation satisfies Case 2. Comparing Figures 4, 11 and 12, we can find that the larger $r_{0}$ is, the better the system will evolve towards (lending, keep the contract).

To explore the effect of the return rate of the SME during normal production on the outcome of the evolutionary game, we set $r_{1}=1 \%$ and $r_{1}=20 \%$. Figures 13 and 14 can be obtained. 


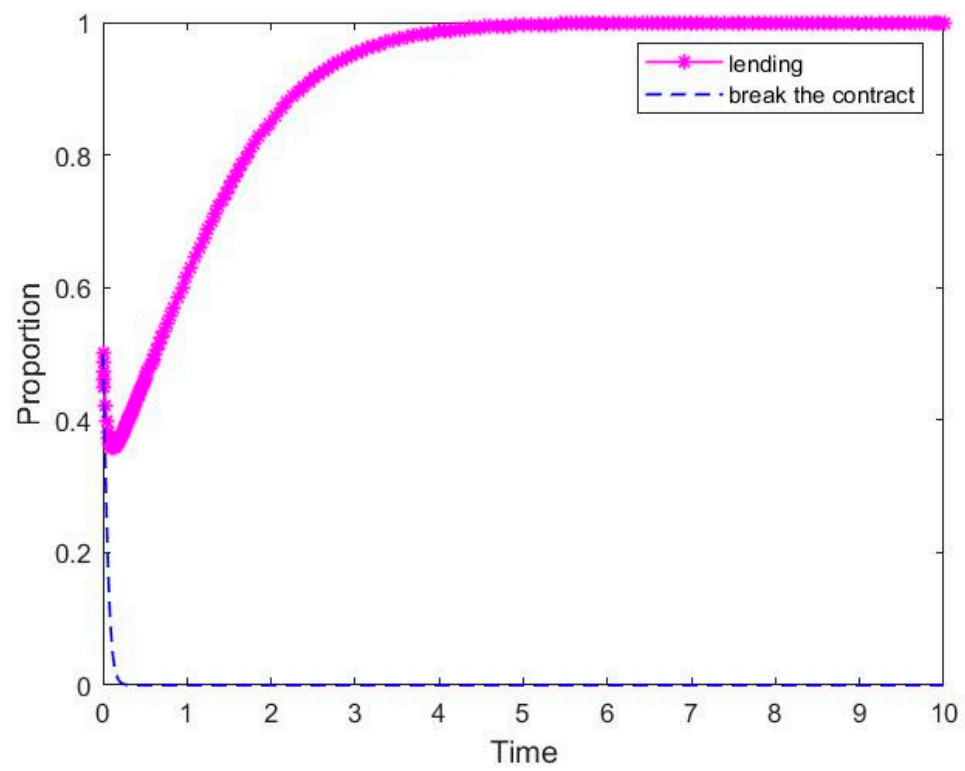

Figure 13. System evolution path diagram $\left(r_{1}=1 \%\right)$.

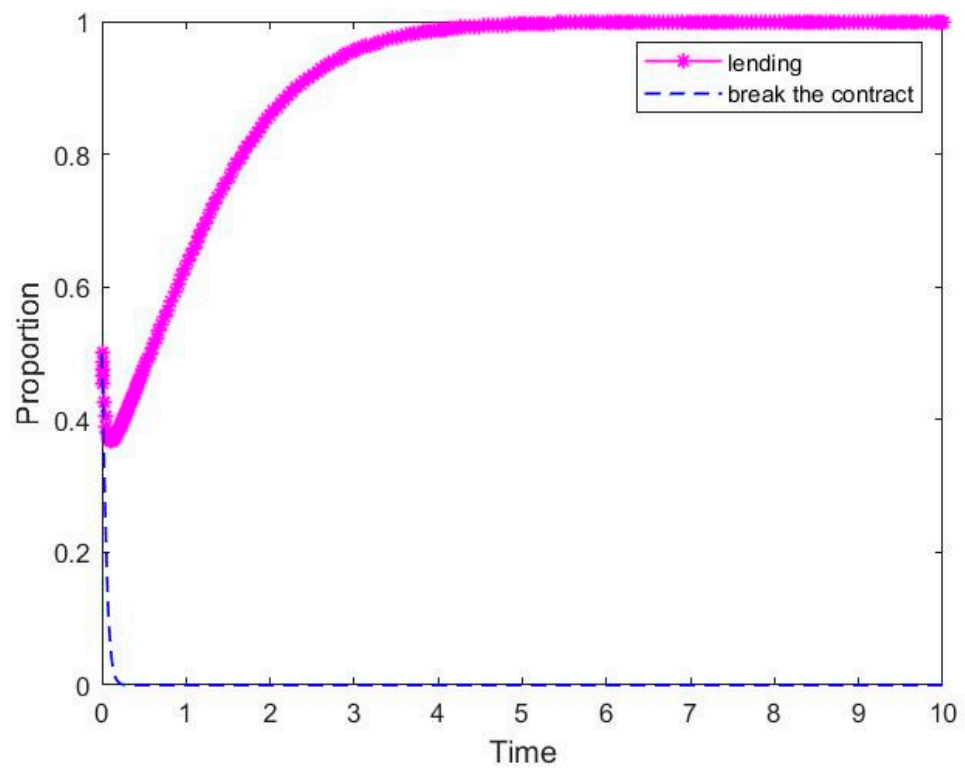

Figure 14. System evolution path diagram $\left(r_{1}=20 \%\right)$.

It can be seen from Figures 13 and 14 that the game evolves towards $x=1$ and $y=0$. This situation satisfies Case 2. Comparing Figures 4, 13 and 14, we can find that the larger $r_{1}$ is, the better the system will evolve towards (lending, keep the contract).

\section{Research Results}

Through the analysis of the established evolutionary game model and numerical simulation, we can obtain the following research results:

- The evolutionary game model will have two different evolutionary cases under different initial conditions: one without ESS and the other with ESS (lending, keep the contract);

- The higher the rate of return during normal production of the SME, the more profits it obtains through normal production. The SME will be more inclined to keep the contract. This is consistent with $[30,31]$. That is, the system will tend to evolve in the 
direction of (lending, keep the contract). As the SME can obtain more profits through production, there is no need to conduct default operations;

- The higher the bank loan interest rate, the more the bank tends to lend. This is because the bank can make more profit by lending. However, the high interest rate means a high capital cost for the SME, which has also been pointed out by [28]. As a result, although the bank tends to lend, the SME may give up loans because it cannot repay the exorbitant interest rate;

- The greater the supply chain punishment when the SME unilaterally breaks the contract, the more likely that the SME will keep the contract. This is consistent with [11]. Therefore, the punishment mechanism of the supply chain is conducive to the evolution of the system to stable equilibrium;

- When the probability of joint loan fraud is small enough or equal to zero, the bank will be able to avoid risks based on the strong credit of the core enterprise. The bank will be happy to carry out SCARPF with the SME, and the SME can solve financing problems. The existence of joint loan fraud is not conducive to the SME obtaining financing;

- The smaller the proportion of income distribution of the SME under joint loan fraud, the less income the SME will obtain through default. Accordingly, its motivation for default will be reduced.

\section{Conclusions}

Based on SCARPF under the condition of confirming the creditor rights of the core enterprise bill, this paper constructs an evolutionary game model of the three parties constituted by the bank, the core enterprise and the SME, considering whether there is a joint loan fraud between the SME and the core enterprise. The ESS was obtained and numerical simulations were performed using data from a technology company. The following conclusions were obtained through research: (1) As the model parameters change, the system will have two evolution cases. The first evolutionary case has no ESS. The ESS for the second evolutionary case is (lending, keep the contract). Limiting the model parameters within a reasonable range is beneficial for SMEs to obtain more financing opportunities, and game participants to obtain more profits in the system; (2) the rate of return during normal production of SMEs, the lending interest rate, the supply chain punishment, the probability that core enterprises and SMEs are involved in joint loan fraud, and the proportion of the benefits to SMEs when engaged in joint loan fraud, will influence the time required to reach the final evolutionary stable state. A higher the rate of return during normal production of SMEs, lending interest rate, and punishment of the supply chain, and a smaller probability of core enterprises and SMEs committing joint loan fraud and proportion of the benefits of SMEs in joint loan fraud, will lead to banks lend more easily and SMEs more easily keep the contract.

On the basis of these conclusions, we present some implications.

(1) In order to solve the financing problems of SMEs and help banks and core enterprises to obtain more profits, the relevant parameters of the model should be limited to a reasonable range. When the conditions of Case 2 are met, the system will evolve in a direction that is beneficial to banks, core enterprises and SMEs. When banks, core enterprises and SMEs make decisions, they should fully consider the decisions that other participants may make and try to make relevant decision parameters meet the conditions of Case 2. This will benefit all game participants in the entire supply chain system to obtain better results.

(2) It is very important that supply chain members make reasonable decisions. Reasonable decisions can help the system reach an evolutionary stable state faster. For banks, they should pay attention to the supervision of core enterprises, focusing on preventing the joint loan fraud of core enterprises and SMEs. When confirming the bill creditor's rights to core enterprises, banks should not only stay at the level of confirmation, but also consider whether there is intentional confirmation to achieve the purpose of joint loan fraud, especially for those core enterprises that have had 
major events of default. Banks can also raise lending interest rates, because the higher the lending interest rate, the more banks tend to lend, and SMEs can increase the availability of financing. However, banks should raise the lending interest rate within an appropriate range. For SMEs, if they want to obtain a benign SCARPF cycle, on the one hand, they must not default on their own contracts and, on the other hand, they must not cooperate with core enterprises to commit joint loan fraud. SMEs should place the growth point of financing income on how to improve their own rate of return during normal production. For core enterprises, they cannot commit joint loan fraud with SMEs. Core enterprises should also increase the punishment when SMEs break the contract. When the punishment is greater, the breach of contract of SMEs will be restricted, and evolution can become a virtuous circle. Based on this, core enterprises should improve the credit investigation system for SMEs that cooperate with themselves for SCARPF, take dishonesty as an important consideration of enterprise cooperation, establish a dishonesty event threshold, and terminate the cooperative relationship after reaching the threshold.

The research also has some limitations, which provide an opportunity for future research. First, to simplify the model, this paper assumes that all information is deterministic in the model. That is, all the game participants know the information in the supply chain. In reality, this is often not the case. Future research can be conducted from the perspective of uncertain information. Second, in reality, the relevant parameters of joint loan fraud are actually difficult to determine. Future research can further optimize the model on joint loan fraud.

Author Contributions: Conceptualization, H.H. and M.T.; methodology, H.H., Y.L. and M.T.; software, Y.L.; validation, Y.L.; investigation, X.C.; resources, H.H.; writing-original draft preparation, Y.L. and M.T.; writing-review and editing, H.H.; supervision, X.C.; project administration, H.H.; funding acquisition, H.H. All authors have read and agreed to the published version of the manuscript.

Funding: This research was funded by the National Natural Science Foundation of China, grant number 71704151; the Soft Science Research Project of Innovation Competence Enhancement Plan of Hebei Province, grant number 21552501D; the Young Top Talent Project of Hebei Higher Education Institutions Humanities and Social Science Research Project, grant number BJ2021079; and the 2021 Hebei Province Social Science Development Research Project, grant number 20210201091.

Institutional Review Board Statement: Not applicable.

Informed Consent Statement: Not applicable.

Data Availability Statement: Not applicable.

Acknowledgments: The authors thank the editors and reviewers for their hard work.

Conflicts of Interest: The authors declare no conflict of interest.

\section{References}

1. Motta, V.; Sharma, A. Lending technologies and access to finance for SMEs in the hospitality industry. Int. J. Hosp. Manag. 2019, 86, 102371. [CrossRef]

2. Lin, M.S.; Song, H.J.; Sharma, A.; Lee, S. Formal and informal SME financing in the restaurant industry: The impact of macroenvironment. J. Hosp. Tour. Manag. 2020, 45, 276-284. [CrossRef]

3. Oztemel, E.; Ozel, S. A conceptual model for measuring the competency level of Small and Medium-sized Enterprises (SMEs). Adv. Prod. Eng. Manag. 2021, 16, 47-66. [CrossRef]

4. Shi, J. The Financial Services Development Report of China's Small, Medium and Micro Enterprises; China Financial Publishing House: Beijing, China, 2020; pp. 1-10.

5. Barkley, B.; Mille, C.K.; Recto, M.C. 2015 Small Business Credit Survey: Report on Employer; Springer: New York, NY, USA, 2016.

6. Chen, X. A model of trade credit in a capital-constrained distribution channel. Int. J. Prod. Econ. 2015, 159, 347-357. [CrossRef]

7. Zhou, Y.W.; Wen, Z.L.; Wu, X. A single-period inventory and payment model with partial trade credit. Comput. Ind. Eng. 2015, 90, 132-145. [CrossRef] 
8. Owens, J.; Wilhelm, L. Alternative Data Transforming SME Finance. 2017. Available online: https://documents.shihang.org (accessed on 1 January 2021).

9. Tsai, K.S. Financing small and medium enterprises in China: Recent trends and prospects beyond shadow banking. Hkust IEMS Work. Paper 2015, 1, 1-47. [CrossRef]

10. Kouvelis, P.; Zhao, W. Who should finance the supply chain? Impact of credit ratings on supply chain decisions. $M \mathcal{E} S O M$ Manuf. Serv. Op. 2018, 20, 19-35.

11. Cao, W.; Ma, C. A game analysis of account receivable financing based on supply chain finance. Commun. Res. 2013, 55, 168-173.

12. Hofmann, E.; Kotzab, H. A supply chain-oriented approach of working capital management. J. Bus. Logist. 2010, 31, 305-330. [CrossRef]

13. Jing, B.; Seidmann, A. Finance sourcing in a supply chain. Decis. Support Syst. 2013, 58, 15-20. [CrossRef]

14. Caniato, F.; Gelsomino, L.M.; Perego, A.; Ronchi, S. Does finance solve the supply chain financing problem? Supply. Chain. Manag. 2016, 21, 534-549. [CrossRef]

15. Yan, N.; Sun, B. Comparative analysis of supply chain financing strategies between different financing modes. J. Ind. Manag. Optim. 2015, 11, 1073-1087. [CrossRef]

16. Shi, J.; Li, Q.; Chu, L.K.; Shi, Y. Effects of demand uncertainty reduction on the selection of financing approach in a capitalconstrained supply chain. Transport. Res. E Log. 2021, 148, 102266. [CrossRef]

17. Wang, M.; Zhao, R.; Li, B. Impact of financing models and carbon allowance allocation rules in a supply chain. J. Clean. Prod. 2021, 302, 126794. [CrossRef]

18. Zhang, Y.; Chen, W.; Li, Q. Third-party remanufacturing mode selection for a capital-constrained closed-loop supply chain under financing portfolio. Comput. Ind. Eng. 2021, 157, 107315. [CrossRef]

19. Yan, N.; Sun, B.; Zhang, H.; Liu, C. A partial credit guarantee contract in a capital-constrained supply chain: Financing equilibrium and coordinating strategy. Int. J. Prod. Econ. 2016, 173, 122-133. [CrossRef]

20. Zhao, J.; Duan, Y. The coordination mechanism of supply chain finance based on tripartite game theory. J. Shanghai Jiaotong Univ. 2016, 21, 370-373. [CrossRef]

21. Gao, G.; Fan, Z.; Fang, X.; Yun, F. Optimal Stackelberg strategies for financing a supply chain through online peer-to-peer lending. Eur. J. Oper. Res. 2018, 267, 585-597. [CrossRef]

22. Jing, B.; Chen, X.; Cai, G. Equilibrium financing in a distribution channel with capital constraint. Prod. Oper. Manag. 2012, 21, 1090-1101. [CrossRef]

23. Wu, D.D.; Yang, L.; Olson, D.L. Green supply chain management under capital constraint. Int. J. Prod. Econ. 2019, $215,3-10$.

24. Yang, H.; Sun, F.; Chen, J.; Chen, B. Financing decisions in a supply chain with a capital-constrained manufacturer as new entrant. Int. J. Prod. Econ. 2019, 216, 321-332. [CrossRef]

25. Luo, Y.; Wei, Q.; Ling, Q.; Huo, B. Optimal decision in a green supply chain: Bank financing or supplier financing. J. Clean. Prod. 2020, 271, 122090. [CrossRef]

26. An, S.; Li, B.; Song, D.; Chen, X. Green credit financing versus trade credit financing in a supply chain with carbon emission limits. Eur. J. Oper. Res. 2021, 292, 125-142. [CrossRef]

27. Jin, W.; Zhang, Q.; Luo, J. Non-collaborative and collaborative financing in a bilateral supply chain with capital constraints. Omega 2019, 88, 210-222. [CrossRef]

28. Lin, Q.; He, J. Supply chain contract design considering the supplier's asset structure and capital constraints. Comput. Ind. Eng. 2019, 137, 106044. [CrossRef]

29. Liu, W.; Long, S.; Xie, D.; Liang, Y.; Wang, J. How to govern the big data discriminatory pricing behavior in the platform service supply chain? An examination with a three-party evolutionary game model. Int. J. Prod. Econ. 2021, 231, 107910. [CrossRef]

30. Cui, H.; Wang, R.; Wang, H. An evolutionary analysis of green finance sustainability based on multi-agent game. J. Clean. Prod. 2020, 269, 121799. [CrossRef]

31. Zhang, Y.; Khan, S.A.R. Evolutionary game analysis of green agricultural product supply chain financing system: COVID-19 pandemic. Int. J. Logist. Res. Appl. 2021, 4, 1-21.

32. Friedman, D. Evolutionary games in economics. Econometrica 1991, 59, 637-666. [CrossRef] 